\title{
Incidence and Prognostic Nomogram for Resected Non-small Cell Neuroendocrine Tumor: A Population-Based Respective Study in China and the SEER Database
}

\author{
Zhaofei Pang \\ Shandong Provincial Hospital $\triangle$ Cheeloo College of Medicine, Shandong University \\ Yong Liu \\ Shandong Provincial Hospital『Cheeloo College of Medicine, Shandong University \\ Xiaogang Zhao \\ The Second Hospital of Shandong University

\section{Guoyuan Ma} \\ Shandong Provincial Hospital, Shandong University

\section{Qidi Zhao} \\ Shandong Provincial Hospital $\mathbb{}$ Cheeloo College of Medicine, Shandong University \\ Jiajun Du ( $\nabla$ dujiajun@sdu.edu.cn ) \\ Shandong Provincial Hospital『Cheeloo College of Medicine, Shandong University
}

\section{Research Article}

Keywords: pulmonary neuroendocrine tumor, nomogram, small cell lung cancer, prognosis

Posted Date: December 20th, 2021

DOI: https://doi.org/10.21203/rs.3.rs-1116500/v1

License: (c) (1) This work is licensed under a Creative Commons Attribution 4.0 International License.

Read Full License 


\section{Abstract}

Background: Pulmonary neuroendocrine tumors, including small cell lung cancer (SCLC) and non-small cell neuroendocrine tumor (NSCLC-NET), have obvious heterogeneity. The comparison between SCLC and NSCLC-NET, and prognostic nomogram of resected NSCLC-NET have not been performed.

Methods: We retrieved patients' information with pulmonary neuroendocrine tumors from SEER database. Age-adjusted incidence and prognostic impacts of histological subtypes, surgery strategies and smoking were compared between SCLC and NSCLC-NET. Independent prognostic factors, screened by Cox regression, were enrolled for prognostic nomogram of resected NSCLC-NET. The nomogram were evaluated and compared to the $8^{\text {th }}$ AJCC TNM staging system. A Chinese cohort was used for external validation.

Results: Age-adjusted incidence of SCLC declined after 1991 but the incidence of NSCLC-NET continuously rose. Patients with typical carcinoid had the best prognosis in both overall survival and lung cancer specific survival after operation. Sleeve and segmental resection were more recommended in NSCLC-NET and SCLC, respectively. High-smoking index was associated with worse prognosis in both SCLC and NSCLC-NET. Histological subtype, age, surgery type, N, M stage and chemotherapy were independent prognostic factors and used to construct prognostic nomogram of resected NSCLC-NET. The nomogram performed well with good discrimination, calibration and clinical usefulness, which was validated by Chinese cohort (1, 3, 5-year AUC: SEER cohort 0.873, 0.901, 0.875; Chinese cohort 0.867, $0.892,0.874)$. Compared to $8^{\text {th }}$ staging system, the nomogram had higher $C$-index $(0.87$ vs $0.728, P<$ $0.001)$, clinical usefulness, increasing AUC value over time and improved $68 \%$. The online server can be accessed at https://nsclc-net-prognostic-prediction.shinyapps.io/DynNomapp/.

Conclusion: NSCLC-NET had increasing incidence over the past decades. The nomogram had high discrimination, calibration and clinical usefulness and performed better than $8^{\text {th }}$ staging system. It may have certain value in risk stratification and survival prediction of patients with resected NSCLC-NET and help clinicians to take measures for high-risk patients in advance.

\section{Introduction}

Neuroendocrine tumor (NET), commonly arising from neuroendocrine cells of gastrointestinal tract, pancreas and lung, is a rare and heterogeneous group of tumors comprising about $2 \%$ of all malignancies (1). NET of lung consists of small-cell lung cancer (SCLC) and non small-cell neuroendocrine tumor (NSCLC-NET), accounting for approximately $25 \%$ of primary lung neoplasms (2). The latter can be further classified into three histological subtypes, including typical carcinoid (TC), large cell neuroendocrine tumor (LCNEC) and atypical carcinoid (AC) (3). Defined by the histological classification based on cell features, mitosis count, and necrosis, SCLC and LCNEC are high-grade malignant tumors with dismal prognosis, and TC and $\mathrm{AC}$ are low- and intermediate-grade tumors with prolonged survival time, respectively (4). A substantial increase of incidence of pulmonary NET has been 
seen over the past 30 years, rising from 0.3 cases per 100,000 in 1973 to 1.35 cases per 100,000 in 2004, which may be partially due to improvement of detecting technology (5). In diagnosis of NET, addition of immunohistochemistry is helpful and often essential, especially in the classification of large-cell neuroendocrine carcinoma (6). Although the four tumors all belong to NET, there is significant distinction in therapy and prognoses. At present, surgical resection is the optimal choice for patients with localized TC and AC $(7,8)$. Moreover, surgical resection is the only curative treatment for TC and AC. The 5- and 10year survival rates of resected TC are both higher than $90 \%$ and the 5 - and 10 -year survival rates of resected $A C$ are $70 \%$ and $50 \%$, respectively (9-11). As for LCNEC and SCLC, comprehensive therapy including surgery, radiation and chemotherapy is still the main treatment method $(12,13)$. Due to delayed diagnosis, early metastasis, drug resistance and frequent relapse, patients with LCNEC or SCLC commonly have a bad prognosis (14-16) .

Despite the increasing incidence, awareness of pulmonary NET is relatively low among thoracic surgeons, who are responsible for diagnosing and treating the patients. Because of heterogeneity of NET and patients themselves, patients of pulmonary NET display obviously different prognoses after operation. If thoracic surgeons and oncologists can make risk stratification for patients of pulmonary NET and predict their prognoses accurately, they will be able to pay more attentions to high-risk patients and take tendentious measures in advance. At present, prognostic model of SCLC has been developed but integrated prognostic model for NSCLC-NET has not been constructed. To predict and improve prognosis of patients with resected NSCLC-NET, it is urgent to develop an integrated prognostic model for NSCLCNET.

In our study, we collected data of pulmonary NET from the Surveillance, Epidemiology, and End Results (SEER) database. To investigate the difference between SCLC and NSCLC-NET, we compared incidences of the two distinct histological subtypes. By Kaplan-Meier analysis, we compared the survival rates, prognostic impacts of surgical type and smoking index between SCLC and NSCLC-NET after operation. Then independent prognostic factors of NSCLC-NET were identified by univariate and multivariate Cox regression analyses and used to establish a prognostic nomogram, which was transformed into an online tool for easy access. Receiver operating characteristic (ROC) curve, calibration plot and decision curve analysis (DCA) were performed to evaluate the discrimination, calibration and clinical usefulness. By calculating concordance index (C-index), net reclassification index (NRI) and time-dependent ROC, we compared advantages of the new model to the 8th edition American Joint Committee on Cancer (AJCC) tumor-nodes-metastasis (TNM) staging system. The data from Shandong province hospital were used for an external validation. To our knowledge, it is the first time that comparison of SCLC and NSCLC-NET, and prognostic nomogram of resected NSCLC-NET have been performed. The study will deepen our understanding for heterogeneity of pulmonary NET and help clinicians to evaluate and improve the prognoses of patients with resected NSCLC-NET.

\section{Methods}

\subsection{Data acquisition and preprocessing}


The data of patients with pulmonary NET diagnosed from 2004 to 2016 were retrieved from 18 population-based cancer registries of the Surveillance, Epidemiology, and End Results (SEER) database via the SEER*Stat program (version 8.3.9). The SEER database is the national Cancer Institute's authoritative source for population-based cancer incidence and survival and encompasses approximately $30 \%$ of the US population (17).

Pulmonary NET includes 4 histological types, SCLC (ICD-0-3: 8041-8045), LCNEC (ICD-0-3: 8013), TC (ICD-0-3: 8240) and AC (ICD-0-3: 8249) according to the 2015 World Health Organization (WHO) Classification of Lung Tumors. In total, 20892 records were collected from 2004 to 2016. Further, 1566 patients were conformed to our inclusion criteria: (i) only primary tumor, (ii) diagnosis confirmed by histology, (iii) surgery performed. The exclusion criteria included: age $<18$, unknown survival time or survival time equal to 0 . Finally, 1527 patients enrolled for analyses. The filtrating flowchart was show in figure 1.

The data included clinical information of patients, survival time, survival status and pathological characteristics. The continuous variables such as age, tumor size were transformed into category variables based on the optimal cutoff value determined by X-tile software. The clinical information included sex (female, male), age at diagnosis, marital status (married, unmarried), primary site (lower lobe, middle lobe, upper lobe, other), laterality (left, right), surgery types (lobectomy, extended lobectomy, pneumonectomy, other), chemotherapy (none/unknown, yes), radiation (none/unknown, yes). The pathological characteristics included laterality (left, right), site of tumor (upper lobe, lower lobe, middle lobe, other), lymph node examination (not examined, examined, unknown), lymph node metastasis (negative, positive) and T, N, M stages. To maintain the latest tumor staging system, the T, N, M stages were updated to the 8th edition AJCC staging system.

\subsection{Statistical analysis}

The age-adjusted incidence information of SCLC and NSCLC-NET from 1975 to 2018 was extracted from SEER database via the SEER*Stat program (version 8.3.9) and visualized by an online tool called dycharts (https://dycharts.com/appv2/\#/pages/home/index). The prognostic impacts of histology subtypes, surgical type and smoking index for SCLC and NSCLC-NET were analyzed by Kaplan-Meier curves. Sex, age at diagnosis, marital status, primary site, laterality, surgery type, chemotherapy, radiation, marital status, T, N and M stage in 8th edition AJCC TNM staging system were enrolled into analysis. Univariate and multivariate Cox regression analyses were performed to screen risk factors and construct a prognostic nomogram. The discrimination of the nomogram was evaluated by ROC. The calibration of the nomogram was assessed by 1,3,5-year calibration plots. The clinical usefulness of the nomogram was evaluated by DCA. In addition, the study compared the new model with the 8th edition AJCC TNM staging system by C-index and NRI and time-dependent ROC. A Chinese cohort consisting of 117 SCLC and 81 NSCLC-NET from Shandong Province Hospital from 2004 to 2016 was collected as an external validation cohort. 
SPSS (version 24) RStudio (version 1.3.1093) and R software (version 4.05) were used for statistical analyses. Continuous variables for two groups were tested by $t$ test when data met the normal distribution and the homogeneity of variance. Otherwise, the Mann-Whitney $U$ test was applied. Categorical variables were compared by the chip-squared test. The cutoff values of continuous variables were determined by the software X-tile. The difference of Kaplan-Meier survival curves was evaluated by log-rank test. R packages including 'survival', 'timeROC', 'rms', 'survminer', 'regplot', 'foreign', 'nricens' and 'shiny' were applied. Two-sided $P<0.05$ was considered as statistical significance. We make sure that all methods were performed according to relevant guidelines and regulations.

\section{Results}

\subsection{Patient characteristics}

Totally, 1527 eligible patients were enrolled for analyses, including 1220 patients with NSCLC-NET and 307 patients with SCLC. The demographics of patients were showed in Table 1. Compared both groups together, patients with NSCLC-NET had longer survival time (median: 49 vs 18 months, $P<0.001$ ). NSCLC-NET was more likely to occur in lower lobes (40.2\%), followed by upper lobes (32.8\%). However, SCLC was more likely occur in upper lobes $(56.4 \%)$, followed by lower lobes $(27.4 \%)$. Patients with SCLC receiving chemotherapy and radiotherapy accounted for $75.2 \%$ and $48.9 \%$, respectively. But only $8.6 \%$ and $4.4 \%$ patients with NSCLC-NET received chemotherapy and radiotherapy. In terms of TNM staging system, more patients with SCLC were in advanced stage than NSCLC-NET during diagnosis $(P<0.001)$. There was no significant difference in marital status $(P=0.849)$ and lymph nodes examination $(P=$ 0.302). In the other characteristics, including sex, laterality of tumor, lymph node positive, tumor size, surgery type, there was certain difference between NSCLC-NET and SCLC $(P<0.05)$. 
Table 1

The demographics of patients with pulmonary neuroendocrine tumors in SEER cohort.

\begin{tabular}{|c|c|c|c|}
\hline Variables & $\begin{array}{l}\text { Non-small cell neuroendocrine tumor } \\
(1220)\end{array}$ & $\begin{array}{l}\text { Small cell lung cancer } \\
(307)\end{array}$ & $\begin{array}{l}P \\
\text { value }\end{array}$ \\
\hline $\begin{array}{l}\text { Age (Median (Q1- } \\
\text { Q3)) }\end{array}$ & $61(50-69)$ & $66(58-72)$ & $<0.001$ \\
\hline \multicolumn{3}{|l|}{ Sex } & \multirow[t]{3}{*}{0.016} \\
\hline Female & $782(64.1 \%)$ & $174(56.7 \%)$ & \\
\hline Male & 438 (35.9\%) & $133(43.3 \%)$ & \\
\hline \multicolumn{3}{|l|}{ Cause } & \multirow[t]{4}{*}{$<0.001$} \\
\hline Alive/Dead (other) & 1092 (89.5\%) & 118 (38.4\%) & \\
\hline Dead/Cancer & 127 (10.4\%) & $188(61.2 \%)$ & \\
\hline $\begin{array}{l}\text { Dead/Unknown } \\
\text { cause }\end{array}$ & $1(0.1 \%)$ & $1(0.3 \%)$ & \\
\hline \multicolumn{3}{|l|}{ Primary_Site } & \multirow[t]{6}{*}{$<0.001$} \\
\hline Lower & $490(40.2 \%)$ & $84(27.4 \%)$ & \\
\hline Middle & $226(18.5 \%)$ & $15(4.9 \%)$ & \\
\hline Upper & $400(32.8 \%)$ & $173(56.4 \%)$ & \\
\hline Other & $69(5.7 \%)$ & $21(6.8 \%)$ & \\
\hline Unknown & $35(2.9 \%)$ & $14(4.6 \%)$ & \\
\hline \multicolumn{3}{|l|}{ Laterality } & \multirow[t]{4}{*}{0.002} \\
\hline Right & 724 (59.3\%) & $165(53.7 \%)$ & \\
\hline Left & $492(40.3 \%)$ & $136(44.3 \%)$ & \\
\hline Other & $4(0.3 \%)$ & $6(2.0 \%)$ & \\
\hline \multicolumn{3}{|l|}{ Chemotherapy } & \multirow[t]{3}{*}{$<0.001$} \\
\hline None/Unknown & $1115(91.4 \%)$ & $76(24.8 \%)$ & \\
\hline Yes & $105(8.6 \%)$ & $231(75.2 \%)$ & \\
\hline \multicolumn{3}{|l|}{ Radiation } & \multirow[t]{3}{*}{$<0.001$} \\
\hline None/Unknown & $1166(95.6 \%)$ & $157(51.1 \%)$ & \\
\hline Yes & $54(4.4 \%)$ & $150(48.9 \%)$ & \\
\hline$T^{8 \text { th }}$ & & & $<0.001$ \\
\hline
\end{tabular}




\begin{tabular}{|c|c|c|c|}
\hline Variables & $\begin{array}{l}\text { Non-small cell neuroendocrine tumor } \\
(1220)\end{array}$ & $\begin{array}{l}\text { Small cell lung cancer } \\
(307)\end{array}$ & $\begin{array}{l}P \\
\text { value }\end{array}$ \\
\hline T1a & 129 (10.6\%) & $15(4.9 \%)$ & \\
\hline $\mathrm{T} 1 \mathrm{~b}$ & 348 (28.5\%) & 53 (17.3\%) & \\
\hline T1c & 201 (16.5\%) & $29(9.4 \%)$ & \\
\hline $\mathrm{T} 2$ & $106(8.7 \%)$ & 48 (15.6\%) & \\
\hline T2a & $100(8.2 \%)$ & $27(8.8 \%)$ & \\
\hline $\mathrm{T} 2 \mathrm{~b}$ & $54(4.4 \%)$ & $16(5.2 \%)$ & \\
\hline T3 & $53(4.3 \%)$ & $19(6.2 \%)$ & \\
\hline $\mathrm{T} 4$ & $31(2.5 \%)$ & $36(11.7 \%)$ & \\
\hline T0+TX & $13(1.1 \%)$ & $12(3.9 \%)$ & \\
\hline Unknown & $185(15.2 \%)$ & $52(16.9 \%)$ & \\
\hline $\mathrm{N}^{8 \text { th }}$ & & & $<0.001$ \\
\hline NO & 694 (56.9\%) & $155(50.5 \%)$ & \\
\hline N1 & $68(5.6 \%)$ & 58 (18.9\%) & \\
\hline $\mathrm{N} 2 / 3$ & 48 (3.9\%) & 87 (28.3\%) & \\
\hline Unknown & $410(33.6 \%)$ & $7(2.3 \%)$ & \\
\hline$M^{8 \text { th }}$ & & & $<0.001$ \\
\hline MO & 775 (63.5\%) & $250(81.4 \%)$ & \\
\hline M1 & $38(3.1 \%)$ & $52(16.9 \%)$ & \\
\hline Unknown & 407 (33.4\%) & $5(1.6 \%)$ & \\
\hline Marital & & & 0.849 \\
\hline Married & $696(57.0 \%)$ & $171(55.7 \%)$ & \\
\hline Unmarried & $460(37.7 \%)$ & $121(39.4 \%)$ & \\
\hline Unknown & $64(5.2 \%)$ & $15(4.9 \%)$ & \\
\hline LN examined & & & 0.302 \\
\hline Not examined & 219 (18.0\%) & $66(21.5 \%)$ & \\
\hline Examined & 999 (81.9\%) & 240 (78.2\%) & \\
\hline Unknown & $2(0.2 \%)$ & $1(0.3 \%)$ & \\
\hline
\end{tabular}




\begin{tabular}{|c|c|c|c|}
\hline Variables & $\begin{array}{l}\text { Non-small cell neuroendocrine tumor } \\
(1220)\end{array}$ & $\begin{array}{l}\text { Small cell lung cancer } \\
(\mathbf{3 0 7 )}\end{array}$ & $\begin{array}{l}P \\
\text { value }\end{array}$ \\
\hline LN positive & & & $<0.001$ \\
\hline Negative & 838 (68.7\%) & $124(40.4 \%)$ & \\
\hline Positive & 161 (13.2\%) & $116(37.8 \%)$ & \\
\hline Unknown & $221(18.1 \%)$ & $67(21.8 \%)$ & \\
\hline Chemotherapy & & & $<0.001$ \\
\hline None/Unknown & 1115(91.4\%) & $76(24.8 \%)$ & \\
\hline Yes & $105(8.6 \%)$ & $231(75.2 \%)$ & \\
\hline Radiation & & & $<0.001$ \\
\hline None/Unknown & 1166(95.6\%) & $157(51.1 \%)$ & \\
\hline Yes & $54(4.4 \%)$ & $150(48.9 \%)$ & \\
\hline Size & & & $<0.001$ \\
\hline$<30 \mathrm{~mm}$ & 872 (71.5\%) & 163 (67.8\%) & \\
\hline$>=30 \mathrm{~mm}$ & 307 (25.2\%) & $111(27.4 \%)$ & \\
\hline unknown & $41(3.4 \%)$ & $33(4.8 \%)$ & \\
\hline Surgery type & & & $<0.001$ \\
\hline Lobectomy & 346 (28.4\%) & 107 (34.9\%) & \\
\hline $\begin{array}{l}\text { Extended } \\
\text { lobectomy }\end{array}$ & $818(67.0 \%)$ & 155 (50.5\%) & \\
\hline Pneumonectomy & 47 (3.9\%) & $11(3.6 \%)$ & \\
\hline Other & $9(0.7 \%)$ & 34 (2.8\%) & \\
\hline
\end{tabular}

\subsection{Age-adjusted incidence of SCLC and NSCLC-NET}

To compare incidence of SCLC and NSCLC-NET, we extracted the age-adjusted incidence information of SCLC and NSCLC-NET from 1975 to 2018. The incidence of SCLC was greatly higher than that of NSCLCNET (Fig. 2A). The initial incidences of SCLC and NSCLC-NET, reported in 1975, were 6.6 and 0.3, respectively. From 1975 to 1991, the incidence of SCLC had been seen a sharp rise from 6.6 to 11.3. After 1991, the incidence slid into decline. In 2018, the incidence declined to 5.1. As for NSCLC-NET, it has shown a gradual uptrend in the past decades, from 0.3 in 1975 to 1.6 in 2018, which indicates NSCLCNET is bringing increasing burden. 
In addition, the study also analyzed the differences of incidence between female and male in SCLC and NSCLC-NET, respectively. Whether in male or female, the trends of incidence of SCLC and NSCLC-NET were consistent with the total incidence. Compared to female, male had higher incidence in SCLC but lower incidence in NSCLC-NET (Fig. 2B, 2C).

\subsection{Comparison of overall survival (OS) and lung cancer specific survival (LCSS) between SCLC and NSCLC-NET}

To explore the survival of patients with resected SCLC and NSCLC-NET, we analyzed the differences of OS and LCSS between SCLC and NSCLC-NET using Kaplan-Meier curve analysis. OS and LCSS of NSCLCNET were both obviously higher than that of SCLC $(P<0.001)$ (5 year survival rate of OS: NSCLC-NET $82.5 \%, 95 \% \mathrm{Cl}$ 0.80-0.85; SCLC: $26.7 \%, 95 \% \mathrm{Cl}: 0.216-0.329 ; 5$ year survival rate of LCSS: NSCLC-NET: $88 \%$, $95 \% \mathrm{Cl} 0.86-0.90$; SCLC: $30.4 \%, 95 \% \mathrm{Cl} 0.251-0.369$ ) (Fig. 3A, 3B). Further, the histology subtypes of NSCLC-NET were classified into three subtypes, including LCNEC, TC and AC. The distinction of OS and LSCC was compared among the four different tumors, respectively (Fig. 3C, 3D). Patients with TC had the best prognosis followed by patients with AC (5 year survival rate of OS: TC: $92.6 \%, 95 \% \mathrm{Cl} 0.906-0.946$; AC: $82.1 \%, 95 \% \mathrm{Cl} 0.731-0.922 ; 5$ year survival rate of LCSS: TC: $97.4 \%, 95 \% \mathrm{Cl} 0.961-0.986$; AC: $86 \% 0.776-$ 0.952). The prognosis of LCNEC was mildly better than that of SCLC (5year survival rate of OS: LCNEC: $31.0 \%, 95 \% \mathrm{Cl} 0.239-0.400$; 5 year survival rate of LCSS: $39.7 \%, 95 \% \mathrm{Cl} 0.321-0.491)$.

\subsection{The impacts of surgical type and smoking index on prognosis of SCLC and NSCLC-NET}

To investigate the impacts of surgical type on prognosis of SCLC and NSCLC-NET, we compared the prognostic difference of SCLC and NSCLC-NET after several common surgery types including local destruction, laser resection, wedge resection, segmental resection, sleeve resection, extended lobectomy, pneumonectomy. In NSCLC-NET, patients receiving sleeve resection had the best prognosis, followed by lobectomy, wedge resection, segmental resection, pneumonectomy (OS $P<0.001$, LCSS $P<0.01$ ) (Fig. 4A, 4B). Nevertheless, patients of SCLC receiving segmental resection had the highest survival rate, followed by lobectomy, local destruction, wedge resection, pneumonectomy, laser resection (OS $P<0.001$, LCSS $P$ $<0.001$ ) (Fig. 4C, 4D). In external validation cohort, the surgical type included lobectomy, extended lobectomy and pneumonectomy. In terms of OS and LCSS, there was no significant difference of prognosis between lobectomy and extended lobectomy but the survival rates of patients receiving the two surgery types were higher than that of patients receiving pneumonectomy (OS $P<0.05$, LCSS $P<0.01$ ) (Fig. 4E, 4F).

Smoking was a recognized hazard factor for lung cancer. To ascertain the effects of smoking amount and time on prognosis of SCLC and NSCLC-NET, we calculated smoking index of each patient in the external validation cohort. Smoking index = smoking amount (cigarette/day) * smoking time (year). The optimal cutoff value of smoking index was determined by X-tile software. The cutoff values of smoking index in NSCLC-NET and SCLC were 600 and 60, respectively. High-smoking index group had worse 
prognosis than low-smoking index group no matter in NSCLC-NET or SCLC (5 year survival rate: NSCLCNET: $P<0.001$, smoking index $<=60061.9 \%, 95 \% \mathrm{Cl} 0.481-0.798$, smoking index $>60044.4 \%, 95 \% \mathrm{Cl}$ 0.345-0.570; SCLC: $P<0.05$, smoking index $<6074.5 \%, 95 \% \mathrm{Cl} 0.642-0.865$, smoking index $>=6043.3 \%$ 95\% Cl 0.265-0.707) (Fig. 5A, 5B).

\subsection{Univariate and multivariate Cox regression analyses}

To predict the prognosis for patients with resected NSCLC-NET, we constructed a prognostic nomogram. The risk factors were screened by univariate and multivariate Cox regression analyses. The result of univariate Cox regression showed that age, sex, primary site of tumor, histological subtype, radiation, chemotherapy, T, N, M stage, size, lymph node positive and surgery type were statistically significant in OS $(P<0.05$ for all) (Table 2). The result of multivariate Cox regression further suggested that age, histological subtype, $\mathrm{N}$ stage, $\mathrm{M}$ stage, surgery type and chemotherapy were independent prognostic factors in OS ( $P<0.05$ for all) (Table 3). Age $>75$ (HR 1.67, 95\%Cl 1.064-2.619, $P=0.026)$, LCNEC (HR 17.159, 95\% Cl 9.762-30.161, $P<0.001$ ), AC (HR 2.964, 95\%Cl 1.433-6.131, $P=0.003$ ), N1 (HR 2.665, $95 \% \mathrm{Cl} 1.657-4.289, P<0.001), \mathrm{N} 2 / 3(\mathrm{HR} 2.695,95 \% \mathrm{Cl} 1.489-4.879, P=0.001)$ and M1 (HR $3.525,95 \% \mathrm{Cl}$ 2.070-6.004, $P<0.001)$ were associated with prolonged OS. Extended lobectomy (HR $0.662,95 \% \mathrm{Cl} 0.447-$ $0.979, P=0.039)$, pneumonectomy (HR 0.686, 95\% $\mathrm{Cl} 0.273-1.726, P=0.423)$ and chemotherapy (HR $0.585,95 \% \mathrm{Cl} 0.352-0.972, P=0.038$ ) were associated with poor prognosis. Similar results of univariate and multivariate Cox regression analyses of LCSS could also be seen in Table 2, 3 . 
Table 2

Univariate Cox regression analysis of overall survival and lung cancer specific survival.

\begin{tabular}{|c|c|c|c|c|c|}
\hline \multirow[t]{2}{*}{ Variables } & \multirow[t]{2}{*}{$\mathrm{n}$} & \multicolumn{2}{|l|}{ Overall Survival (OS) } & \multicolumn{2}{|l|}{$\begin{array}{l}\text { Lung Cancer Specific } \\
\text { Survival(LCSS) }\end{array}$} \\
\hline & & $\mathrm{HR}(95 \% \mathrm{Cl})$ & $\begin{array}{l}P \\
\text { Value }\end{array}$ & $\mathrm{HR}(95 \% \mathrm{Cl})$ & $P$ Value \\
\hline Age & 1220 & & $<0.001$ & & $<0.001$ \\
\hline$<=75$ & 1061 & 1 & & 1 & \\
\hline$>75$ & 119 & $3.51(2.536-4.858)$ & & $2.154(1.356-3.419)$ & \\
\hline Sex & 1220 & & $<0.001$ & & $<0.001$ \\
\hline Female & 782 & 1 & & 1 & \\
\hline Male & 438 & $1.792(1.365-2.353)$ & & $2.042(1.442-2.892)$ & \\
\hline Primary site & 1185 & & $<0.001$ & & $<0.001$ \\
\hline Lower & 490 & 1 & - & 1 & - \\
\hline Middle & 226 & $0.646(0.396-1.054)$ & 0.08 & $0.538(0.27-1.074)$ & 0.079 \\
\hline Upper & 400 & $1.945(1.43-2.645)$ & $<0.001$ & $2.111(1.428-3.121)$ & $<0.001$ \\
\hline Other & 69 & $0.996(0.513-1.934)$ & 0.99 & $1.393(0.653-2.972)$ & 0.391 \\
\hline Laterality & 1216 & & 0.618 & & 0.86 \\
\hline Right & 724 & 1 & & 1 & \\
\hline Left & 492 & $1.073(0.814-1.414)$ & & $1.032(0.724-1.472)$ & \\
\hline Histology & 1220 & & $<0.001$ & & $<0.001$ \\
\hline Typical carcinoid & 933 & 1 & - & 1 & - \\
\hline LCNEC & 183 & $\begin{array}{l}13.352(9.946- \\
17.924)\end{array}$ & $<0.001$ & 31.72 (20.211-49.784) & $<0.001$ \\
\hline Atypical carcinoid & 104 & 2.299 (1.343-3.935) & 0.002 & $5.645(2.882-11.057)$ & $<0.001$ \\
\hline Radiation & 1220 & & $<0.001$ & & $<0.001$ \\
\hline None/Unknown & 1166 & 1 & & 1 & \\
\hline Yes & 54 & $6.271(4.328-9.087)$ & & $8.889(5.886-13.424)$ & \\
\hline Chemotherapy & 1220 & & $<0.001$ & & $<0.001$ \\
\hline None/Unknown & 1115 & 1 & & & \\
\hline Yes & 105 & $5.401(3.94-7.405)$ & & $7.899(5.471-11.406)$ & \\
\hline
\end{tabular}




\begin{tabular}{|c|c|c|c|c|c|}
\hline \multirow[t]{2}{*}{ Variables } & \multirow[t]{2}{*}{ n } & \multicolumn{2}{|l|}{ Overall Survival (OS) } & \multicolumn{2}{|l|}{$\begin{array}{l}\text { Lung Cancer Specific } \\
\text { Survival(LCSS) }\end{array}$} \\
\hline & & $\mathrm{HR}(95 \% \mathrm{Cl})$ & $\begin{array}{l}P \\
\text { Value }\end{array}$ & $\mathrm{HR}(95 \% \mathrm{Cl})$ & $P$ Value \\
\hline $\mathrm{T}$ & 1027 & & $<0.001$ & & $<0.001$ \\
\hline T1 & 663 & 1 & - & 1 & - \\
\hline T2 & 251 & $1.484(1.066-2.065)$ & 0.019 & $2.045(1.334-3.134)$ & 0.001 \\
\hline T3 & 49 & $2.748(1.641-4.602)$ & $<0.001$ & $4.741(2.658-8.458)$ & $<0.001$ \\
\hline T4 & 28 & $2.672(1.298-5.499)$ & 0.008 & $4.980(2.356-10.526)$ & $<0.001$ \\
\hline $\mathbf{N}$ & 810 & & $<0.001$ & & $<0.001$ \\
\hline NO & 694 & 1 & - & 1 & - \\
\hline N1 & 68 & $3.324(2.181-5.065)$ & $<0.001$ & $3.696(2.287-5.973)$ & $<0.001$ \\
\hline $\mathrm{N} 2 / 3$ & 48 & $4.574(2.962-7.063)$ & $<0.001$ & $5.605(3.463-9.074)$ & $<0.001$ \\
\hline$M$ & 813 & & $<0.001$ & & $<0.001$ \\
\hline MO & 775 & 1 & & 1 & \\
\hline M1 & 38 & 6.078 (3.965-9.319) & & 7.899 (5.04-12.382) & \\
\hline Marital & 1156 & & 0.094 & & 0.736 \\
\hline Married & 696 & 1 & & 1 & \\
\hline unmarried & 460 & $1.269(0.96-1.677)$ & & $1.064(0.742-1.527)$ & \\
\hline Size & 1179 & & $<0.001$ & & $<0.001$ \\
\hline$<30 \mathrm{~mm}$ & 872 & & & & \\
\hline$>=30 \mathrm{~mm}$ & 307 & $1.904(1.433-2.531)$ & & $2.729(1.915-3.888)$ & \\
\hline LN examined & 1162 & & 0.822 & & 0.152 \\
\hline Not examined & 219 & $1.04(0.741-1.459)$ & & $0.692(0.419-1.145)$ & \\
\hline Examined & 943 & 1 & & 1 & \\
\hline LN positive & 993 & & $<0.001$ & & $<0.001$ \\
\hline Negative & 838 & 1 & & 1 & \\
\hline Positive & 155 & $4.131(2.995-5.699)$ & & $5.125(3.469-7.571)$ & \\
\hline Surgery type & & & 0.02 & & 0.087 \\
\hline Lobectomy & 331 & 1 & - & 1 & - \\
\hline
\end{tabular}




\begin{tabular}{|c|c|c|c|c|c|}
\hline \multirow[t]{2}{*}{ Variables } & \multirow[t]{2}{*}{$\mathrm{n}$} & \multicolumn{2}{|c|}{ Overall Survival (OS) } & \multicolumn{2}{|c|}{$\begin{array}{l}\text { Lung Cancer Specific } \\
\text { Survival(LCSS) }\end{array}$} \\
\hline & & $\mathrm{HR}(95 \% \mathrm{Cl})$ & $\stackrel{P}{\text { Value }}$ & $\mathrm{HR}(95 \% \mathrm{Cl})$ & $P$ Value \\
\hline $\begin{array}{l}\text { Extended } \\
\text { lobectomy }\end{array}$ & 799 & 0.736 & 0.048 & 0.947 & 0.947 \\
\hline Pneumonectomy & 45 & 1.42 & 0.234 & 1.987 & 1.987 \\
\hline
\end{tabular}


Table 3

Multivariate Cox regression analysis of overall survival and lung cancer specific survival.

\begin{tabular}{|c|c|c|c|c|}
\hline \multirow[t]{2}{*}{ Variables } & \multicolumn{2}{|c|}{ Overall Survival (OS) } & \multicolumn{2}{|c|}{ Lung Cancer Specific Survival(LCSS) } \\
\hline & $\mathrm{HR}(95 \% \mathrm{Cl})$ & $P$ Value & $\mathrm{HR}(95 \% \mathrm{Cl})$ & $P$ Value \\
\hline \multicolumn{5}{|l|}{ Age } \\
\hline$<=75$ & 1 & - & 1 & - \\
\hline$>75$ & 1.670 & 0.026 & 1.651 & 0.06 \\
\hline \multicolumn{5}{|l|}{ Histology } \\
\hline Typical carcinoid & 1 & - & 1 & - \\
\hline LCNEC & 17.159 & $<0.001$ & 44.677 & $<0.001$ \\
\hline Atypical carcinoid & 2.964 & 0.003 & 7.288 & $<0.001$ \\
\hline \multicolumn{5}{|c|}{$\mathbf{N}$} \\
\hline NO & 1 & - & 1 & - \\
\hline N1 & 2.665 & $<0.001$ & 3.067 & $<0.001$ \\
\hline $\mathrm{N} 2 / 3$ & 2.695 & 0.001 & 2.887 & 0.002 \\
\hline \multicolumn{5}{|l|}{ M } \\
\hline MO & 1 & - & 1 & - \\
\hline M1 & 3.525 & $<0.001$ & 4.062 & $<0.001$ \\
\hline \multicolumn{5}{|l|}{ Surgery } \\
\hline Lobectomy & 1 & & 1 & - \\
\hline Extended lobectomy & 0.662 & 0.039 & 0.591 & 0.029 \\
\hline Pneumonectomy & 0.686 & 0.423 & 0.340 & 0.092 \\
\hline \multicolumn{5}{|l|}{ Chemotherapy } \\
\hline None/Unknown & 1 & - & 1 & - \\
\hline Yes & 0.585 & 0.038 & 0.675 & 0.136 \\
\hline
\end{tabular}

\subsection{Development and evaluation of the prognostic nomogram}

The independent prognostic factors in OS including age, histological subtype, $\mathrm{N}, \mathrm{M}$, surgery type and chemotherapy were used to establish a nomogram for predicting OS of NSCLC-NET (Fig. 6A). The nomogram showed that histological subtype contributed the most to the prognosis, followed by $\mathrm{M}$ stage, 
$\mathrm{N}$ stage, age, surgery type and chemotherapy. Each variable was assigned a score and the total points were calculated by summing up scores of the six variables. The survival probability of patients was estimated by drawing a straight line down to 1-, 3-, 5-year survival probability scale from the total points scale.

To evaluate the discrimination, calibration, clinical usefulness, we draw ROC curves, calibration plot and DCA curves of the nomogram, respectively. The ROC curves manifested that the nomogram had good discrimination (1-, 3-, 5-year area under curve (AUC): 0.873, 0.901, 0.875) (Fig. 6B). The calibration plot also performed well (Fig. 6C). Compared to the 8th edition AJCC TNM staging system, the nomogram had obvious advantages in clinical usefulness due to good net benefit with wide and practical ranges of threshold probabilities (Fig. 6D-6F). In addition, the nomogram had higher C-index (0.87) than the 8th edition AJCC TNM staging system $(0.728)(P<0.001)$. By calculating NRI, the nomogram improved $68 \%$ in contrast to the 8th edition AJCC TNM staging system. By 'timeROC' package, we drew the timedependent ROC curves. It suggested that the nomogram had higher discrimination than the 8th edition AJCC TNM staging system and the difference was statistically significant after 20 months (Fig. 6G, 6H).

\subsection{External validation of the nomogram by the Chinese cohort}

In order to validate the accuracy of the nomogram, we collected a Chinese cohort to validate the nomogram. The demographics of the validation cohort were showed in Table 4. We drew the ROC curves, calibration plot and DCA curves in the validation cohort, which was similar to the SEER cohort. ROC curves and calibration plot showed that the nomogram was appropriate for Chinese patients (1-, 3-, 5-year AUC: $0.867,0.892,0.874$ ) (Fig. 7A, 7B). The 1, 3, 5 year DCA curves displayed the nomogram indeed surpassed the 8th edition AJCC TNM staging system (Fig. 7C-7E). 
Table 4

The demographics of patients with pulmonary neuroendocrine tumors in Chinese cohort.

\begin{tabular}{|c|c|c|c|}
\hline Variables & $\begin{array}{l}\text { Non-small cell neuroendocrine } \\
\text { tumor (81) }\end{array}$ & $\begin{array}{l}\text { Small cell lung } \\
\text { cancer (117) }\end{array}$ & $\begin{array}{l}P \\
\text { value }\end{array}$ \\
\hline $\begin{array}{l}\text { Survival (Median (Interquartile } \\
\text { range) (months) }\end{array}$ & $58(70.25)$ & $50(72)$ & 0.292 \\
\hline Age (Median (Interquartile range)) & $55(14)$ & $58(13)$ & 0.218 \\
\hline Sex & & & 0.843 \\
\hline Female & $26(32.1 \%)$ & $36(30.8 \%)$ & \\
\hline Male & $55(67.9 \%)$ & $81(69.2 \%)$ & \\
\hline Status & & & 0.023 \\
\hline Alive & $52(64.2 \%)$ & $56(47.9 \%)$ & \\
\hline Dead & $29(35.8 \%)$ & $61(52.1 \%)$ & \\
\hline Laterality & & & 0.01 \\
\hline right & $51(63.0 \%)$ & $52(44.4 \%)$ & \\
\hline left & $30(37.0 \%)$ & $65(55.6 \%)$ & \\
\hline Primary Site & & & 0.031 \\
\hline Lower & $22(27.2 \%)$ & $43(36.8 \%)$ & \\
\hline Middle & $10(12.3 \%)$ & $3(2.6 \%)$ & \\
\hline Upper & $35(43.2 \%)$ & $55(47.0 \%)$ & \\
\hline Other & $14(17.3 \%)$ & $16(13.7 \%)$ & \\
\hline Surgery type & & & 0.072 \\
\hline Lobectomy & $62(76.5 \%)$ & $87(74.4 \%)$ & \\
\hline Extended lobectomy & $12(14.8 \%)$ & $9(7.7 \%)$ & \\
\hline Pneumonectomy & $7(8.6 \%)$ & $21(17.9 \%)$ & \\
\hline T stage & & & 0.19 \\
\hline T1 & $46(56.8 \%)$ & $50(42.7 \%)$ & \\
\hline $\mathrm{T} 2$ & $24(29.6 \%)$ & $43(36.8 \%)$ & \\
\hline T3 & $5(6.2 \%)$ & $15(12.8 \%)$ & \\
\hline $\mathrm{T} 4$ & $6(7.4 \%)$ & $9(7.7 \%)$ & \\
\hline N stage & & & $<0.001$ \\
\hline
\end{tabular}




\begin{tabular}{|llll|}
\hline Variables & $\begin{array}{l}\text { Non-small cell neuroendocrine } \\
\text { tumor (81) }\end{array}$ & $\begin{array}{l}\text { Small cell lung } \\
\text { cancer (117) }\end{array}$ & $\begin{array}{l}P \\
\text { value }\end{array}$ \\
\hline N0 & $51(63.0 \%)$ & $35(29.9 \%)$ & \\
\hline N1 & $12(14.8 \%)$ & $40(34.2 \%)$ & \\
\hline N2/3 & $18(22.2 \%)$ & $42(35.9 \%)$ & \\
\hline M stage & & & \\
\hline M0 & $81(100.0 \%)$ & $117(100.0 \%)$ & \\
\hline Chemotherapy & & & \\
\hline No & $55(67.9 \%)$ & $37(31.6 \%)$ & \\
\hline Yes & $16(19.8 \%)$ & $66(56.4 \%)$ & \\
\hline Unknown & $10(12.3 \%)$ & $14(12.0 \%)$ & \\
\hline Radiation & & $71(66.4 \%)$ & \\
\hline No & $62(76.5 \%)$ & $23(21.5 \%)$ & \\
\hline Yes & $9(11.1 \%)$ & $13(12.1 \%)$ & \\
\hline Unknown & $10(12.3 \%)$ & $36(30.8 \%)$ & \\
\hline Size & & $81(69.2 \%)$ & \\
\hline$<30 m m$ & $36(44.4 \%)$ & & \\
\hline$>=30 m m$ & $45(55.6 \%)$ & & \\
\hline
\end{tabular}

\subsection{Construction of webserver for easy access of the predicting nomogram}

For convenient use for clinicians, we constructed an online tool via 'shiny' package (Fig. S1). The webserver could be accessed at https://nsclc-net-prognostic-prediction.shinyapps.io/DynNomapp/. When essential clinical information was input, the matched survival time or probability would be displayed in the form of figures or tables.

\section{Discussion}

Lung cancer is one of the most common malignancies and remains the leading cause of cancer-related death worldwide (18). Pulmonary NET approximately accounts for $25 \%$ lung primary tumors, including TC (<1\%), LCNEC (3\%), AC (2\%) and SCLC $(20 \%)(2,19)$. With the changes of environment, life habits, the profiles of lung cancer have changed gradually over the past decades (20). The incidence of SCLC is decreased but the incidence of NSCLC-NET is on the contrary, which gradually comes into view and 
brings more and more medical burden. Due to heterogeneity of NET, there is great difference of diagnosis, treatment and prognosis in SCLC and NSCLC-NET. Thus it is necessary to explore the difference between the two histological subtypes. Despite the prognostic model of SCLC has been reported, the prognostic nomogram for NSCLC-NET is still absent (20). Currently, predicting prognosis of NSCLC-NET mainly depends on TNM staging system. It has been well recognized that NSCLC-NET has obviously distinct prognosis with the other cancers. Therefore, the TNM staging system is not accurate enough to predict the prognosis of NSCLC-NET. To our knowledge, it is the first time that a prognostic nomogram has been constructed for guidance on prognosis of NSCLC-NET after operation.

In our study, we found that the incidence of NSCLC-NET had gradually increased but the incidence of SCLC had decreased since 1991. Moreover, female had higher incidence than male in NSCLC-NET, which meant NSCLC-NET may become the major subtype of pulmonary NET and bring bigger threat to female in the future. As for survival rate, patients with resected NSCLC-NET have significant better prognosis than SCLC. Further analysis demonstrated that TC had the highest 5 year survival rate, followed by AC, LCNEC and SCLC. The prognosis of LCNEC was similar to SCLC. It is worth noting, LCNEC is so similar to SCLC in its biological, clinical, and prognostic characteristics that LCNEC is excluded in some studies of large cell lung cancer $(21,22)$. According to WHO Classification Lung Tumors Classification [2015], LCNEC had been grouped with other neuroendocrine tumors (3).

In NSCLC-NET, patients receiving sleeve resection had the best prognosis but in SCLC, patients receiving segmental resection had the best prognosis. To some extent, sleeve and segmental resections conserve more lung function and is helpful for patients to recover as soon as possible, which may explain that patients with sleeve and segmental resection has better prognosis. The security and efficiency of sleeve resection has been validated in some studies (23). It is well recognized that smoking plays an important role in initiation and progression of lung cancer. Cigarette contains multiple carcinogenic substances (24). Smoking is also considered as a most common risk factor in development of chronic obstructed pulmonary disease(25). By analyzing smoking index, we found the higher the smoking index, the worse the prognosis in both SCLC and NSCLC-NET. It has been reported that SCLC has a strong association with cigarette smoking. About 95\% SCLC patients have a history of heavy tobacco exposure (26).

The nomogram comprised six key factors, age, histological type, $\mathrm{N}$ stage, $\mathrm{M}$ stage, chemotherapy and surgery procedure. Age, $\mathrm{N}$ stage, and $\mathrm{M}$ stage are common prognostic factors in many cancers. Nomograms of many other cancers also include the three factors $(27,28)$. As for histological type, NSCLC-NET is an integrated cancer containing TA, AC, LCNEC. In fact, although the three cancers all derive from neuroendocrine cells and belong to non-small cells morphologically, they have distinct differentiation. TA, AC, and LCNEC are low-, intermediate- and high-grade tumors, respectively, which suggests that they have different malignant degrees (4). High-grade tumors commonly have stronger proliferation, invasion and metastasis, thus worse prognosis $(29,30)$. Many molecular makers associated with proliferation and epithelial-mesenchymal transformation have been developed to predict prognoses of cancer patients $(31,32)$. For advanced TA and AC, cytotoxic chemotherapeutic regimens are recommended. However, a standard chemotherapeutic regimen has not been established (8). Extended 
lobectomy has more chance to eliminate residues of tumor cells than lobectomy and reduces relapse and metastasis. Compared to pneumonectomy, extended lobectomy conserves more pulmonary function so that patients can recover faster and obtain higher quality of life (33). 1, 3, 5-year AUC of the nomogram were $0.873,0.901,0.875$ and the $\mathrm{C}$-index was higher than the conventionally used 8 th edition AJCC staging system $(0.87$ vs $0.728, P<0.001)$, indicating that the new nomogram had a strong discrimination. The calibration plot suggested that the predicting OS was highly consistent with the observed OS. In addition, compared to the 8th edition AJCC staging system, DCA demonstrated that the new nomogram had higher clinical usefulness. In 2020, Dong et al. constructed a predicting nomogram for OS of TC with 3, 5-year ROC of 0.824 and 0.812 (34). The nomogram for OS of AC developed by Chen et al. had 3-, 5-year AUC of $0.722,0.737$ (35). He et al. reported a predicting nomogram for OS of LCNEC with C-index of 0.75 (36). Thus, compared to the published nomograms, our nomogram not only integrated prediction for three subtypes of pulmonary NET but also had stronger predicting ability.

Our study has some advantages as follows. Firstly, our study was based on a large-scale population from the United States and validated by a Chinese cohort, which ensures reliability of our conclusion. Secondly, the study comprehensively compared SCLC and NSCLC-NET, including age-adjusted incidence, OS, LCSS, impacts of treatment strategies and smoking index on prognosis. Thirdly, it is first time that prognostic nomogram of NSCLC-NET has been established and evaluated by multiple methods such as C-index, ROC, calibration plot, DCA. Moreover, comparison with the 8th edition AJCC TNM staging system also demonstrated that the nomogram had better performance and certain clinical value. Last but not least, for convenient use for clinicians, we drew an online tool via 'shiny' package, which could easily show the predicting survival rate across time by inputting corresponding clinical features.

However, there are still some limitations in the study. First, it is a retrospective study so selection bias is difficult to avoid. Second, due to limitation of dataset, there are still some recognized factors affecting prognosis such as chronic obstructive pulmonary disease (COPD), drinking, specific chemotherapy regimen not included in the study. Last, the validation cohort from Shandong province hospital is not a multicenter data.

\section{Conclusion}

In conclusion, NSCLC-NET had increasing incidence over the past decades. Sleeve and segmental resection were more recommended in NSCLC-NET and SCLC, respectively. Smoking was associated with poor prognosis in both NSCLC-NET and SCLC. Moreover, prognostic nomogram of resected NSCLC-NET consisting of histological subtype, age, surgery type, $\mathrm{N}, \mathrm{M}$ stage and chemotherapy performed better than the 8th TNM staging system. Thus, it may have potential value in risk stratification and survival prediction of patients with resected NSCLC-NET and help clinicians to take measures for high-risk patients in advance.

\section{Declarations}


Acknowledgements

The authors thank all patients, investigators, and institutions involved in these studies.

\section{Funding}

This work is supported by Natural Science Foundation of Shandong Province (Grant No. ZR2020QH215) and Natural Science Foundation of Shandong Province (Grant No.ZR2020QH214).

\section{Ethics approval and consent to participate}

The patients in the China and SEER database could not be identified, so the analyses and reporting of the data in our study were exempt from review by the Ethics Board of Shandong Provincial Hospital Affiliated to Shandong University. The requirement for written informed consent to participate was also waived.

\section{Competing interests}

There is no competing interest regarding the publication of this paper.

\section{Authors' contributions}

Zhaofei Pang, Yong Liu and Jiajun Du carried out the design of this study, analyses of statistics and draft the manuscript. Zhaofei Pang, Yong Liu, Xiaogang Zhao, Guoyuan Ma and Qidi Zhao performed collection of the statistics and prepared the manuscript. All authors read and approved the final manuscript.

\section{Consent for publication Availability of data and materials}

Not applicable.

\section{References}

1. Oronsky B, Ma PC, Morgensztern D, Carter CA. Nothing But NET: A Review of Neuroendocrine Tumors and Carcinomas. Neoplasia. 2017;19(12).

2. Rekhtman N. Neuroendocrine tumors of the lung: an update. Arch Pathol Lab Med. 2010;134(11):1628-38.

3. Travis WD, Brambilla E, Nicholson AG, Yatabe Y, Austin JHM, Beasley MB, et al. The 2015 World Health Organization Classification of Lung Tumors: Impact of Genetic, Clinical and Radiologic Advances Since the 2004 Classification. J Thorac Oncol. 2015;10(9):1243-60.

4. Pelosi G, Papotti M, Rindi G, Scarpa A. Unraveling tumor grading and genomic landscape in lung neuroendocrine tumors. Endocr Pathol. 2014;25(2):151-64.

5. Yao JC, Hassan M, Phan A, Dagohoy C, Leary C, Mares JE, et al. One hundred years after "carcinoid": epidemiology of and prognostic factors for neuroendocrine tumors in 35,825 cases in the United 
States. J Clin Oncol. 2008;26(18):3063-72.

6. Borczuk AC. Pulmonary Neuroendocrine Tumors. Surg Pathol Clin. 2020;13(1):35-55.

7. Caplin ME, Baudin E, Ferolla P, Filosso P, Garcia-Yuste M, Lim E, et al. Pulmonary neuroendocrine (carcinoid) tumors: European Neuroendocrine Tumor Society expert consensus and recommendations for best practice for typical and atypical pulmonary carcinoids. Ann Oncol. 2015;26(8):1604-20.

8. Hendifar AE, Marchevsky AM, Tuli R. Neuroendocrine Tumors of the Lung: Current Challenges and Advances in the Diagnosis and Management of Well-Differentiated Disease. J Thorac Oncol. 2017;12(3):425-36.

9. Rea F, Rizzardi G, Zuin A, Marulli G, Nicotra S, Bulf R, et al. Outcome and surgical strategy in bronchial carcinoid tumors: single institution experience with 252 patients. Eur $\mathrm{J}$ Cardiothorac Surg. 2007;31(2):186-91.

10. Detterbeck FC. Management of carcinoid tumors. Ann Thorac Surg. 2010;89(3).

11. Cardillo G, Sera F, Di Martino M, Graziano P, Giunti R, Carbone L, et al. Bronchial carcinoid tumors: nodal status and long-term survival after resection. Ann Thorac Surg. 2004;77(5):1781-5.

12. Kalemkerian GP, Schneider BJ. Advances in Small Cell Lung Cancer. Hematol Oncol Clin North Am. 2017;31(1):143-56.

13. Kinslow CJ, May MS, Saqi A, Shu CA, Chaudhary KR, Wang TJC, et al. Large-Cell Neuroendocrine Carcinoma of the Lung: A Population-Based Study. Clin Lung Cancer. 2020;21(2).

14. Saltos A, Shafique M, Chiappori A. Update on the Biology, Management, and Treatment of Small Cell Lung Cancer (SCLC). Front Oncol. 2020;10:1074.

15. Ogawa H, Sakai Y, Nishio W, Fujibayashi Y, Nishikubo M, Nishioka Y, et al. DLL3 expression is a predictive marker of sensitivity to adjuvant chemotherapy for pulmonary LCNEC. Thorac Cancer. 2020;11(9):2561-9.

16. Hiroshima K, Mino-Kenudson M. Update on large cell neuroendocrine carcinoma. Transl Lung Cancer Res. 2017;6(5):530-9.

17. Doll KM, Rademaker A, Sosa JA. Practical Guide to Surgical Data Sets: Surveillance, Epidemiology, and End Results (SEER) Database. JAMA Surg. 2018;153(6):588-9.

18. Siegel RL, Miller KD, Fuchs HE, Jemal A. Cancer Statistics, 2021. CA Cancer J Clin. 2021;71(1):7-33.

19. Travis WD, Brambilla E, Burke AP, Marx A, Nicholson AG. Introduction to The 2015 World Health Organization Classification of Tumors of the Lung, Pleura, Thymus, and Heart. J Thorac Oncol. 2015;10(9):1240-2.

20. Barta J, Powell C, Wisnivesky J. Global Epidemiology of Lung Cancer. Annals of global health. 2019;85(1).

21. Asamura $H$, Kameya $T$, Matsuno $Y$, Noguchi $M$, Tada $H$, Ishikawa $Y$, et al. Neuroendocrine neoplasms of the lung: a prognostic spectrum. J Clin Oncol. 2006;24(1):70-6. 
22. Lin G, Qi K, Liu B, Liu H, Li J. A nomogram prognostic model for large cell lung cancer: analysis from the Surveillance, Epidemiology and End Results Database. Transl Lung Cancer Res. 2021;10(2):62235 .

23. Tronc F, Grégoire J, Rouleau J, Deslauriers J. Long-term results of sleeve lobectomy for lung cancer. Eur J Cardiothorac Surg. 2000;17(5):550-6.

24. Loeb LA, Ernster VL, Warner KE, Abbotts J, Laszlo J. Smoking and lung cancer: an overview. Cancer Res. 1984;44(12 Pt 1):5940-58.

25. Vij N, Chandramani-Shivalingappa P, Van Westphal C, Hole R, Bodas M. Cigarette smoke-induced autophagy impairment accelerates lung aging, COPD-emphysema exacerbations and pathogenesis. Am J Physiol Cell Physiol. 2018;314(1):C73-C87.

26. Bernhardt E, Jalal S. Small Cell Lung Cancer. Cancer treatment and research. 2016;170:301-22.

27. Jiang S, Zhao R, Li Y, Han X, Liu Z, Ge W, et al. Prognosis and nomogram for predicting postoperative survival of duodenal adenocarcinoma: A retrospective study in China and the SEER database. Sci Rep. 2018;8(1):7940.

28. Zhou H, Zou X, Li H, Chen L, Cheng X. Construction and validation of a prognostic nomogram for primary vulvar melanoma: a SEER population-based study. Jpn J Clin Oncol. 2020;50(12):1386-94.

29. Delahunt B, Eble JN, Egevad L, Samaratunga H. Grading of renal cell carcinoma. Histopathology. 2019;74(1).

30. Elston CW, Ellis IO. Pathological prognostic factors in breast cancer. I. The value of histological grade in breast cancer: experience from a large study with long-term follow-up. Histopathology. 1991;19(5):403-10.

31. Cao R, Yuan L, Ma B, Wang G, Qiu W, Tian Y. An EMT-related gene signature for the prognosis of human bladder cancer. J Cell Mol Med. 2020;24(1):605-17.

32. Peters G, Gongoll S, Langner $\mathrm{C}$, Mengel M, Piso P, Klempnauer J, et al. IGF-1R, IGF-1 and IGF-2 expression as potential prognostic and predictive markers in colorectal-cancer. Virchows Arch. 2003;443(2):139-45.

33. Hong TH, Cho JH, Shin S, Kim HK, Choi YS, Zo Jl, et al. Extended sleeve lobectomy for centrally located non-small-cell lung cancer: a 20-year single-centre experience. Eur J Cardiothorac Surg. 2018;54(1):142-8.

34. Dong S, Liang J, Zhai W, Yu Z. Development and Validation of an Individualized Nomogram for Predicting Overall Survival in Patients With Typical Lung Carcinoid Tumors. Am J Clin Oncol. 2020;43(9):607-14.

35. Chen X, Pang Z, Wang Y, Bie F, Zeng Y, Wang G, et al. The role of surgery for atypical bronchopulmonary carcinoid tumor: Development and validation of a model based on Surveillance, Epidemiology, and End Results (SEER) database. Lung Cancer. 2020;139.

36. He Y, Liu H, Wang S, Chen Y. Prognostic nomogram predicts overall survival in pulmonary large cell neuroendocrine carcinoma. PLoS One. 2019;14(9):e0223275. 
Figures

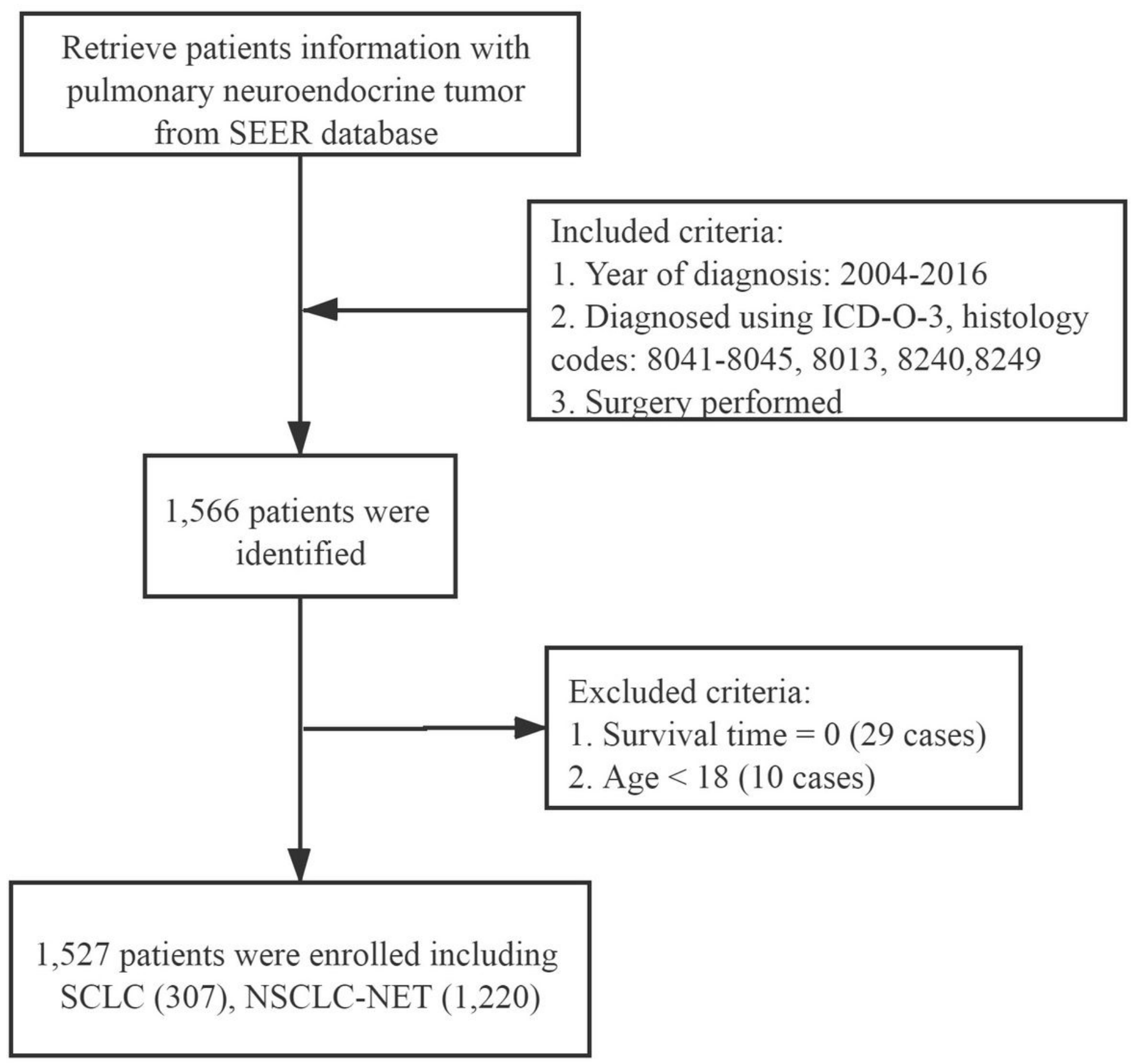

Figure 1

The flowchart of patients with pulmonary neuroendocrine tumor selected from the SEER database. 
A

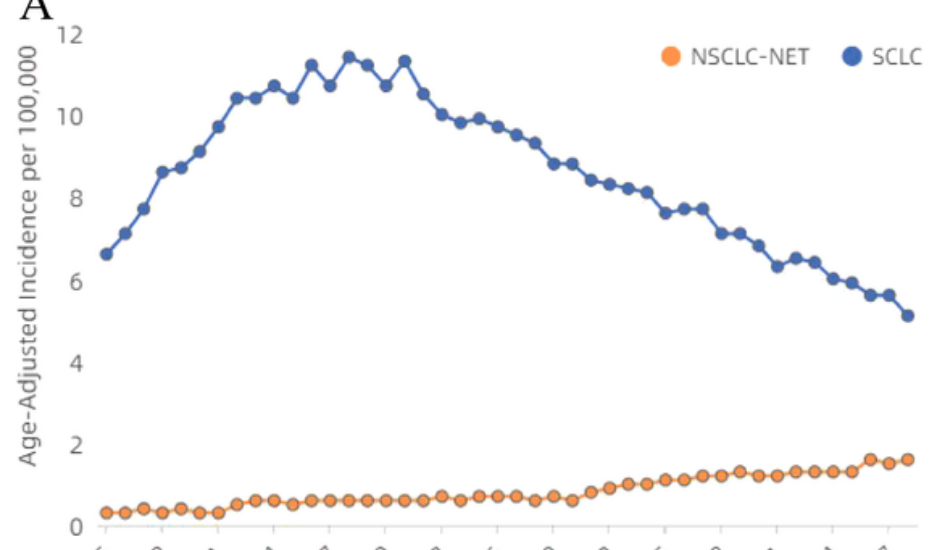

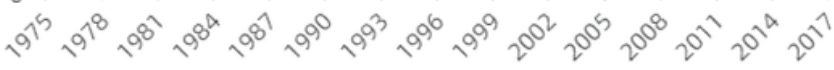

$\mathrm{C}$

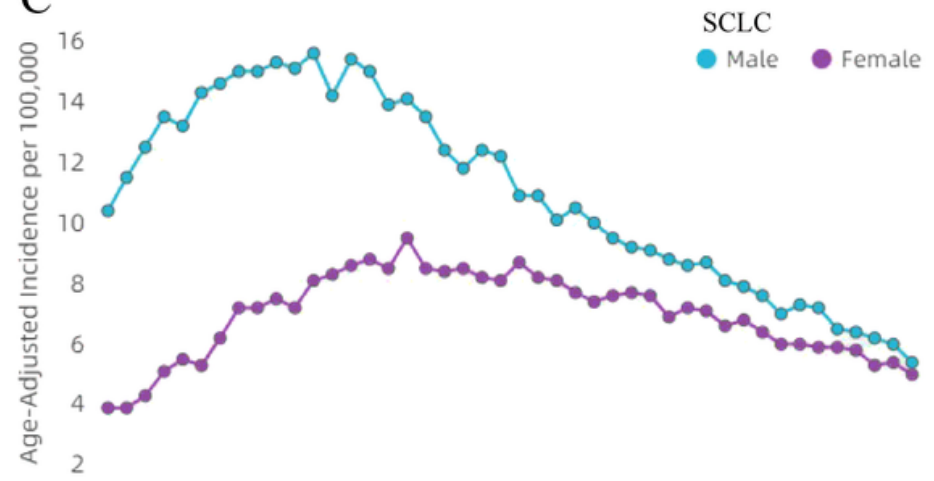

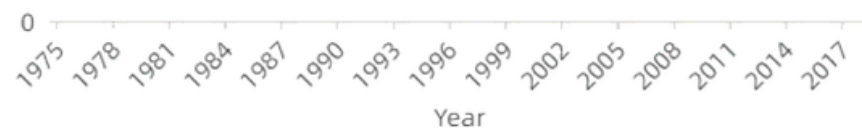

B

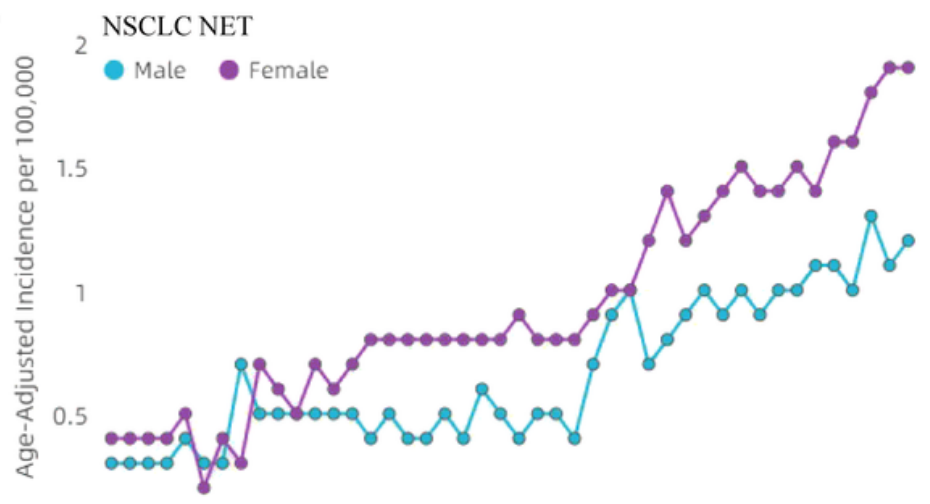

0

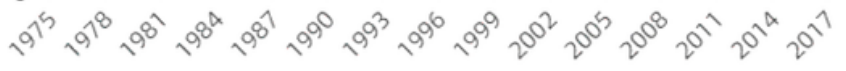

\section{Figure 2}

The age-adjusted incidence of small cell lung cancer (SCLC) and non-small cell neuroendocrine tumor (NSCLC-NET) from 1975 to 2018. (A) Comparison of total age-adjusted incidence between SCLC and NSCLC-NET. Comparison of age-adjusted incidences of female and male in NSCLC-NET (B) and SCLC (C). 
A

Histology — NSCLC-NET — SCLC

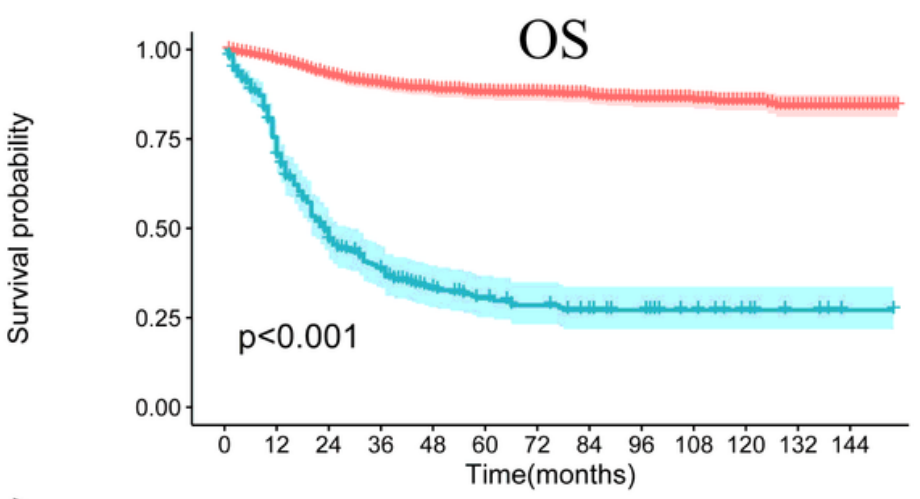

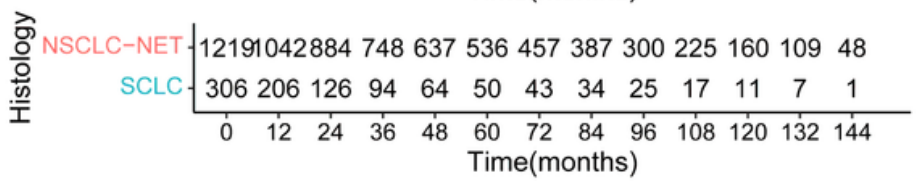

$\mathrm{C}$
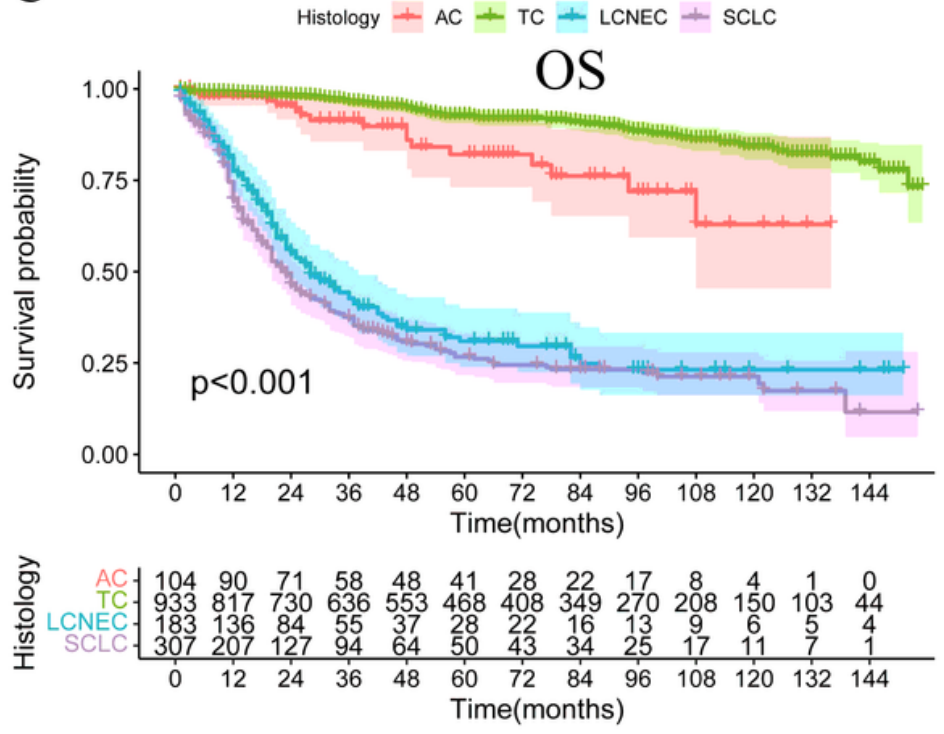

$\mathrm{B}$
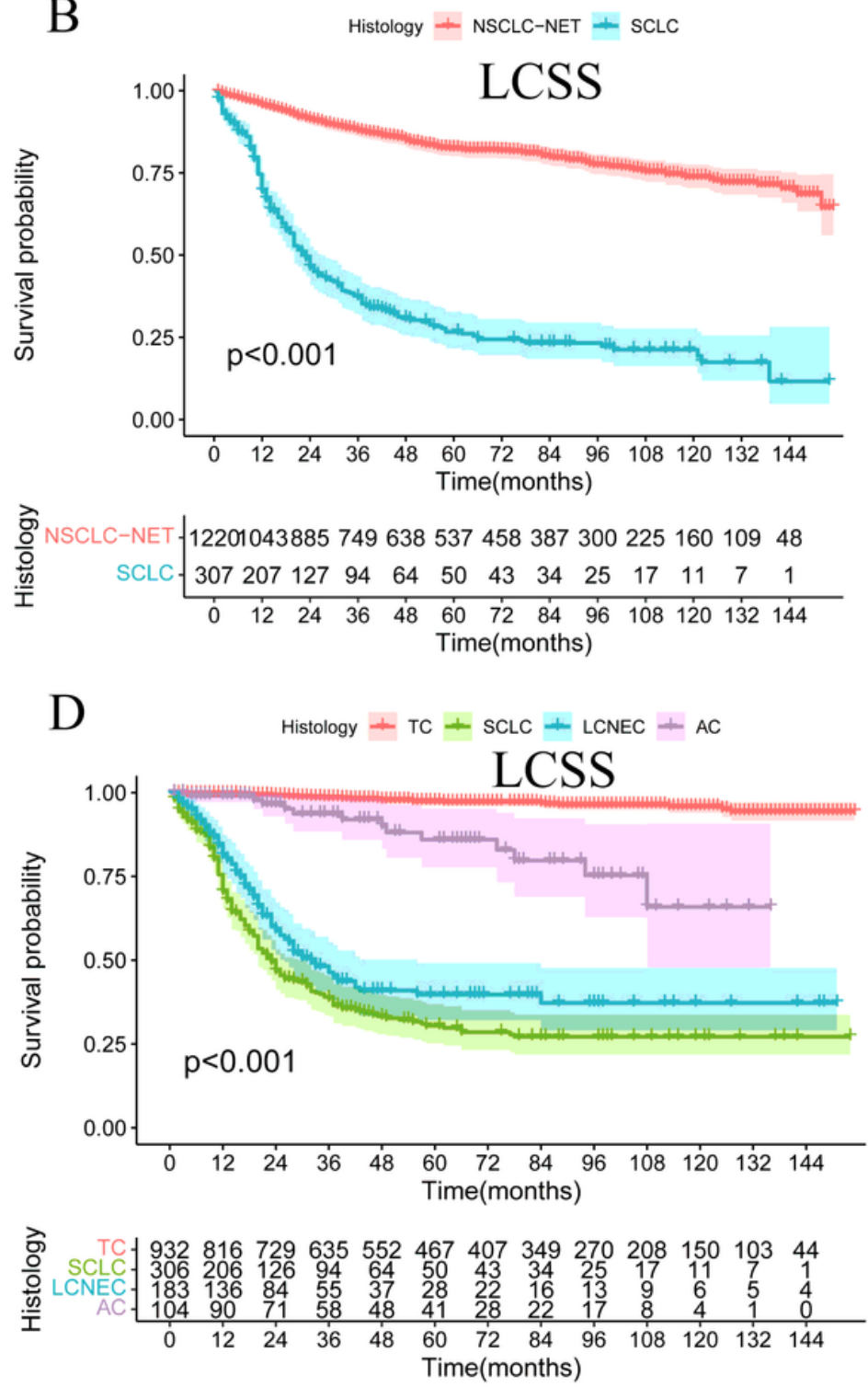

Figure 3

Kaplan-Meier survival analyses of different histological subtypes of pulmonary neuroendocrine tumors.

Analyses of overall survival (OS) (A) and lung cancer specific survival (LCSS) (B) in SCLC and NSCLCNET. Analyses of OS and LCSS in four histological subtypes including typical carcinoid, atypical carcinoid, large cell neuroendocrine tumor and SCLC. Log-rank test was used to detect the statistical difference of survival curves and $P<0.05$ was considered to be statistically significant. 

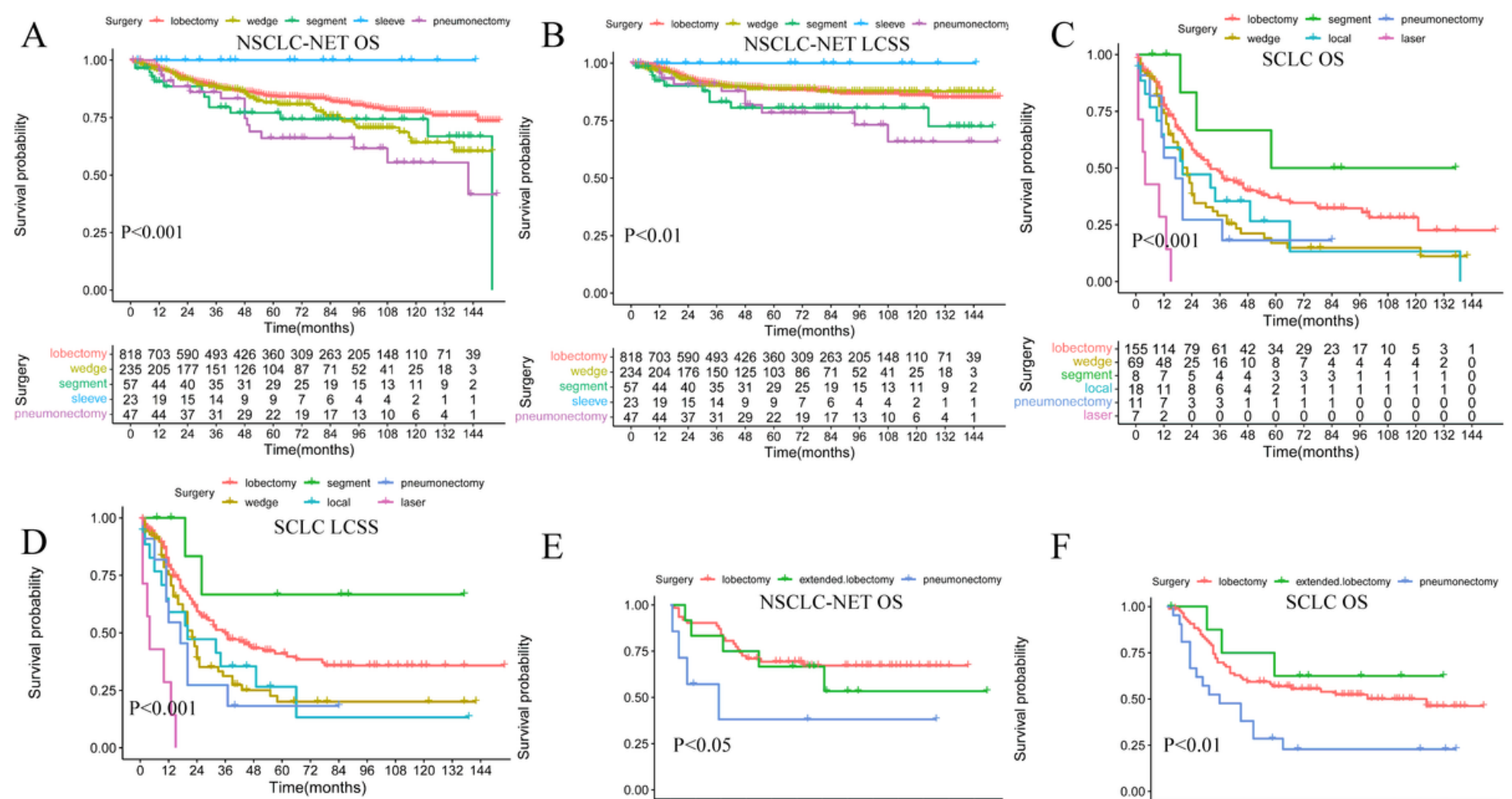

E

F
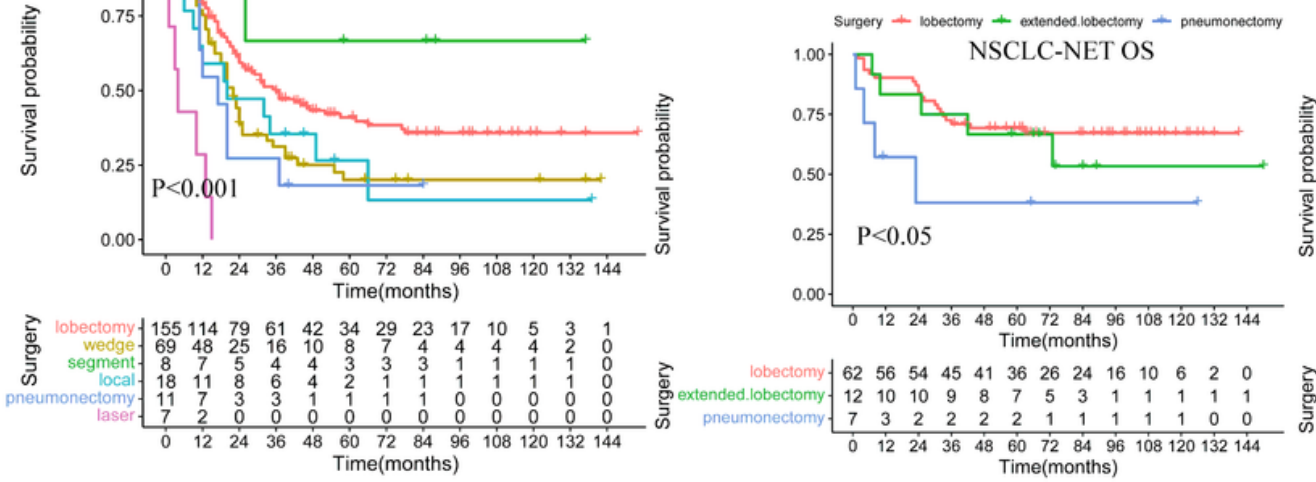

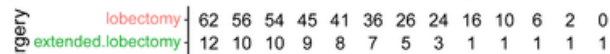

\$

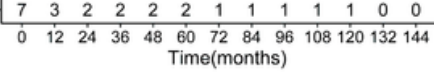

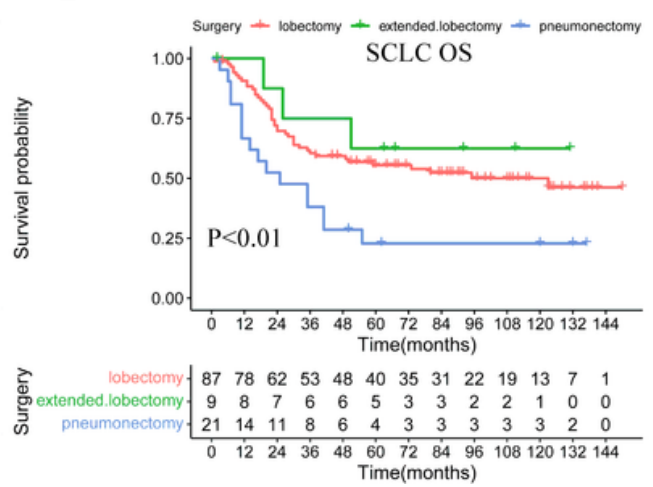

Figure 4

The prognostic impacts of surgery types on NSCLC-NET and SCLC. The Kaplan-Meier analyses of OS (A) and LCSS (B) in patients with NSCLC-NET after receiving different surgery types, including lobectomy, wedge resection, segmental resection, sleeve resection and pneumonectomy in SEER cohort. The KaplanMeier analyses of OS (C) and LCSS (D) in patients with SCLC after receiving different surgery types, including lobectomy, wedge resection, segmental resection, sleeve resection and pneumonectomy in SEER cohort. The Kaplan-Meier analyses of OS in patients with NSCLC-NET (E) or SCLC (F) after receiving different surgery types, including lobectomy, extended lobectomy and pneumonectomy in Chinese cohort. Log-rank test was used to detect the statistical difference of survival curves and $\mathrm{P}<0.05$ was considered to be statistically significant. 

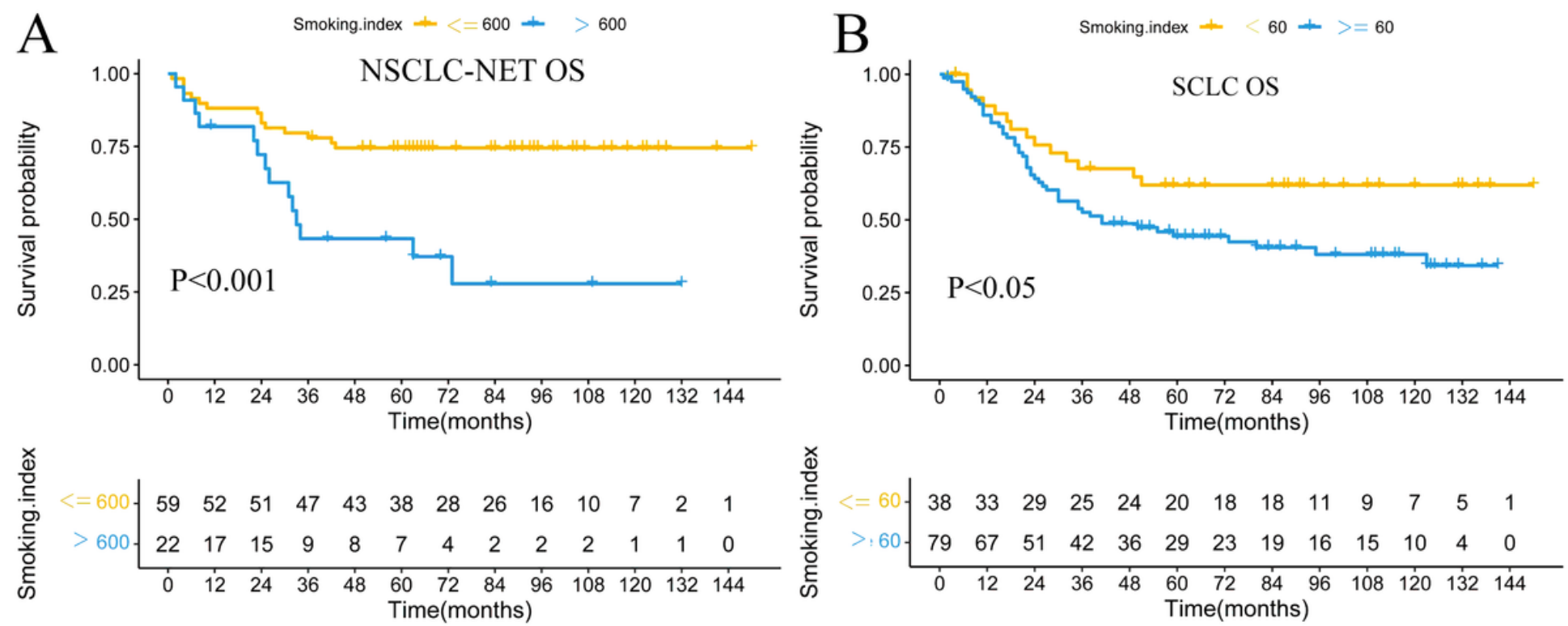

\section{Figure 5}

The prognostic impacts of smoking index on NSCLC and SCLC. The survival difference between highand low-smoking index groups in NSCLC (A) and SCLC (B). Log-rank test was used to detect the statistical difference of survival curves and $\mathrm{P}<0.05$ was considered to be statistically significant. 

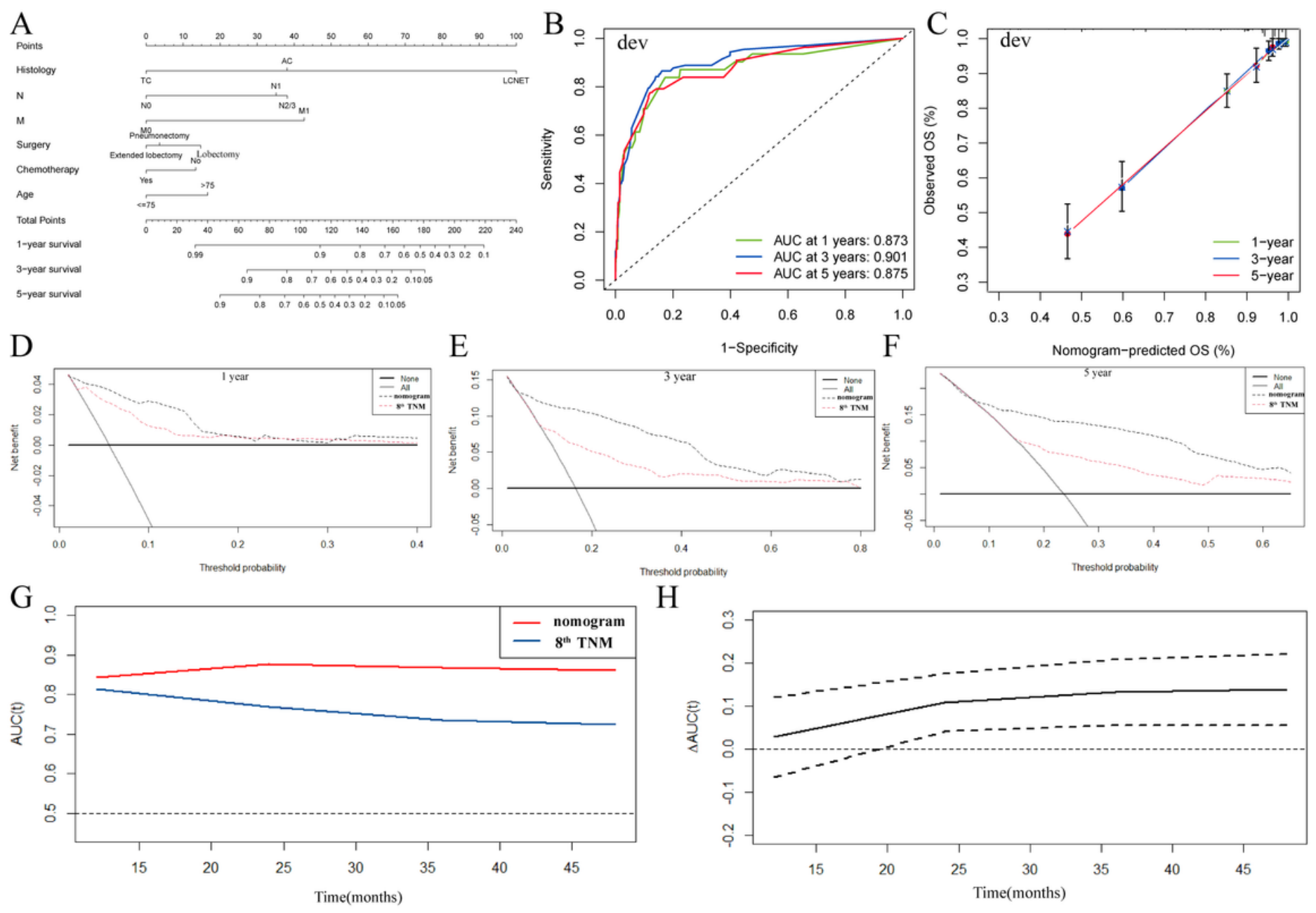

\section{Figure 6}

Development and validation of prognostic nomogram of resected NSCLC-NET. (A) The prognostic nomogram of resected NSCLC-NET consisting of histological subtype, N stage, M stage, surgery type, chemotherapy and age. (B) 1-, 3-, 5-year receiver operating characteristic (ROC) of the nomogram (1-, 3-, 5year area under curve (AUC): $0.873,0.901,0.875)$. (C) 1-, 3-, 5-year calibration plots of the nomogram. The horizontal axis represents predicted OS by the nomogram and the vertical axis represents actual OS of patients. The decision curve analysis (DCA) of the nomogram. (D) 1-year DCA; (E) 3-year DCA; (F) 5-year DCA. (G) Time-dependent ROC curves of nomogram and $8^{\text {th }}$ edition AJCC TNM staging system. $(H)$ The $\triangle A U C$ of the both models $=$ time-dependent AUC value of nomogram - time-dependent AUC value of $8^{\text {th }}$ edition AJCC TNM staging system. The dotted lines represent 95\% confidence interval (Cl). 
A

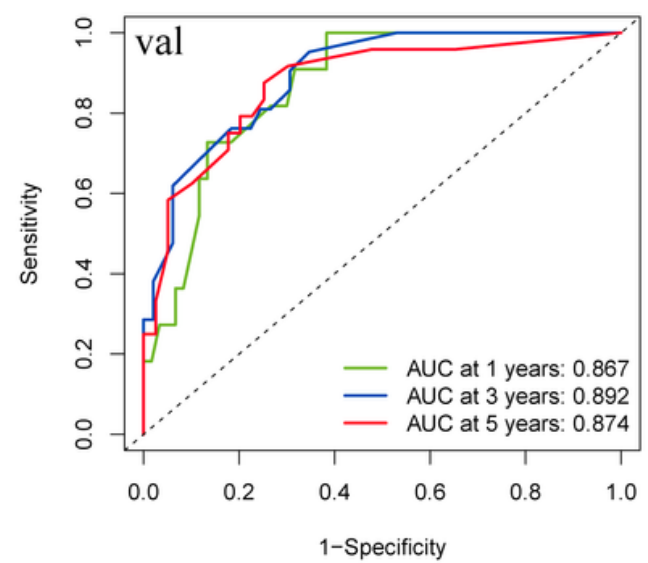

B

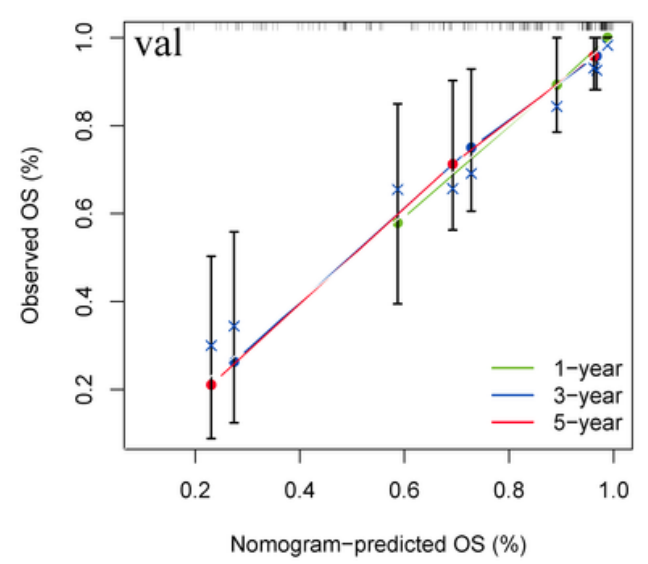

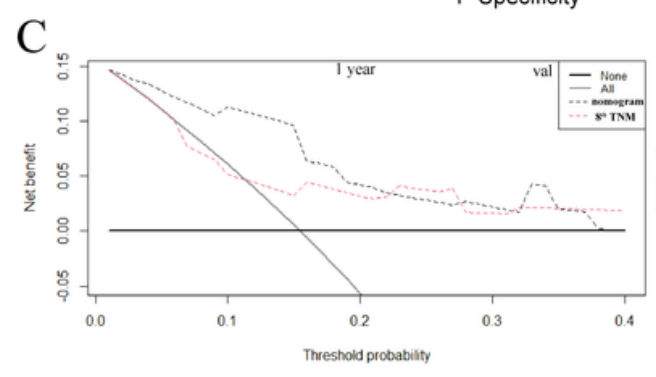

$\mathrm{D}$

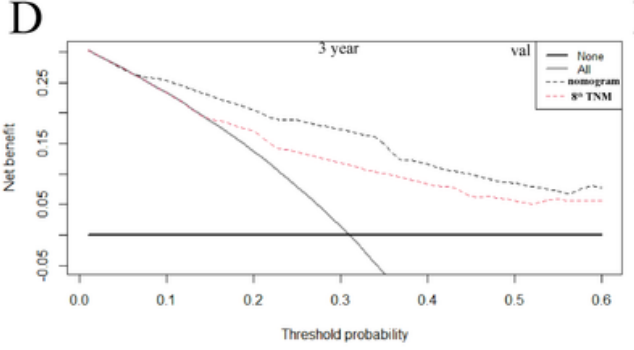

E

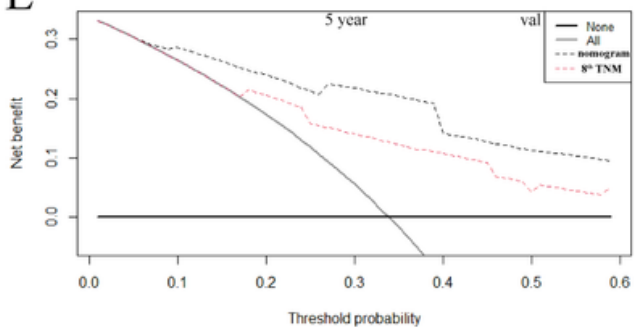

Figure 7

External validation of the nomogram via a Chinese cohort. (A) 1-, 3-, 5-year ROC of the nomogram (1-, 3-, 5-year AUC: $0.867,0.892,0.874)$. (B) 1-, 3-, 5-year calibration plots of the nomogram. The decision curve analysis (DCA) of the nomogram. (C) 1-year DCA; (D) 3-year DCA; (E) 5-year DCA.

\section{Supplementary Files}

This is a list of supplementary files associated with this preprint. Click to download.

- Supplementfigure1.png

- Supplementinformation.docx 